\title{
Study on Landscape Design of Agroecological Sightseeing Garden---A Case Study of Huaguo Mountain International Ecological Holiday Resort in Chishui, Guizhou
}

\author{
Lu Tan ${ }^{1}$ and Baisong Lu ${ }^{2}$ \\ ${ }^{1}$ Urban and Rural Construction Branch, Chengdu Vocational College of Agricultural Science and \\ Technology, Chengdu, Sichuan Province, Zip code: 610000
}

${ }^{2}$ Chongqing Aerospace Vocational and Technical College, Chongqing, Zip code: 400000

\section{Keywords: Agroecological; Landscape; Economy; Sustainable}

\begin{abstract}
This paper analyzes the key points of ecological landscape space design in the planning of Agroecological Sightseeing Garden according to the living example. Use theoretical knowledge to establish regional characteristics of agricultural ecological style and create a sustainable development of Agroecological Sightseeing Garden, which can promote the sustainable development of surrounding economy.

In recent years, people's living standards continue to increase because of the rapid economic development. Along with the continuous development of science and technology, traffic conditions improve and tourism has also been rapid development. The development of sightseeing agriculture has responded to Chinese policy for building a new socialist countryside. Therefore, urban people can return to rural areas and experience rural customs. At the same time, adjust the rural industrial structure, increase rural employment opportunities improve farmers' income and promote healthy and steady development of rural areas. However, the planning and design of most agroecological sightseeing garden in China is still at the preliminary stage of development. Such as simply paste and put together some of the traditional regional symbols on architecture, which lead to similar scenic design and low population acceptance. Finally, it cannot play a catalytic role in tourism and regional economic development. Based on the design concept of the Santo Huaguo Mountain Project in Daba Village, Chishui City, Guizhou Province, this paper expounds the innovation of landscape planning and design in the specific agroecological sightseeing garden, improve the surrounding tourism industry chain and promote economic sustainable development.
\end{abstract}

\section{Geography Position and Background}

Chishui Huaguo Mountain project is located in the southwest and 34 kilometers away from Chishui city, Guizhou province. Chishui City is located in the most northwest of Guizhou Province, which is located at $105^{\circ} 36^{\prime} 35^{\prime \prime}$ east longitude and $28^{\circ} 17^{\prime} 02^{\prime \prime}$ north latitude. It extends from $105^{\circ} 36^{\prime}$ to $106^{\circ} 15^{\prime}$ at east longitude and $28^{\circ} 16^{\prime}$ to $28^{\circ} 46^{\prime}$ at north latitude. It is 61.85 kilometers long from west to east and 55.35 kilometers long from north to south. Chishui City is located in the middle and lower reaches of the Chishui River, bordering on the south of Sichuan Province. It is an important gateway to Guizhou and Sichuan Province and known as "Sichuan-Guizhou Key Lock" and "Qianbei Border Town". The forest coverage rate of Chishui is $80.3 \%$, ranking first in Guizhou Province. Huaguo Mountain project belongs to the transitional zone between Sichuan Basin and Yunnan-Guizhou Plateau, which belongs to the typical sub-tropical humid monsoon climate. There is a pleasant climate without cold winter and hot summer. People of Han and Miao live together and the total population is 6887 . The ecological plants are protected well and forest coverage rate is $93 \%$, ranking first in Chishui city. Besides, bamboo resources, tourism resources and water resources are extremely rich. Here is the place which a national 4A-level scenic spots - Chishui Great Falls Scenic Area and Swallow Rock Forest Park locate. 


\section{Design Concept}

The theme of the whole landscape is "International Ecological Holiday Resort of Milan". Through the refinement and sublimation of Bamboo Township's history, culture, art and local traditions and customs, and combining business, leisure and tourism, the project will be built into a comprehensive international agroecological sightseeing garden which can integrate sightseeing, tourism, participation and leisure together and adapt to the requirements of modern development, such as regionalization, folklore and industrialization.

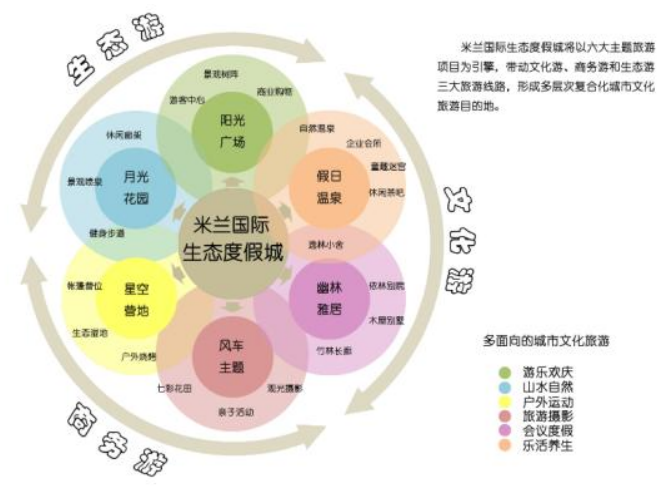

Figure 1

From the nature of surrounding landscapes and landscape linkages and road systems planned by the city, different functional models of landscape nodes will be created. Mainly divided into: square area, central landscape area, parking area, hot spring center area, hotel resort, residential area, ecological wetland, ecological fruit forest theme area, camping area. Please find overall planning and design for details. The spatial structure is that main landscape nodes of the park are distributed around the central axis of the main entrance. It shows like that: Entrance Square - Recreational Landscape Area - Orchard Picking Area - Ecological Wetland - Camping Experience Area Specialty Leisure Accommodation Area. This design make the main attractions of the park form a sightseeing tour link, which can provided to different age groups of leisure, entertainment and tourism area. At the same time, this also constitutes the spatial structure of the whole agroecological sightseeing garden. This small area of forest closed landscape patterns is formed through forest around park (fruit trees, green forest) plate connected, which can maintain the park microclimate relatively stable, conserve water and reduce the park's soil erosion. Different plates increase the biodiversity of the system and the artificial water surface increases the artistic beauty.

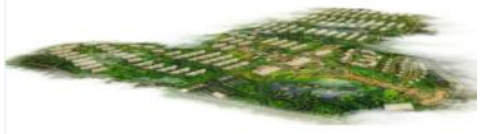

Figure 2. General Layout

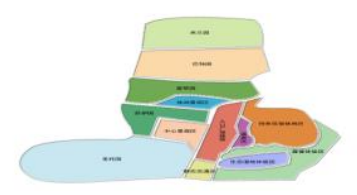

Figure 3. Function Zoning Map 


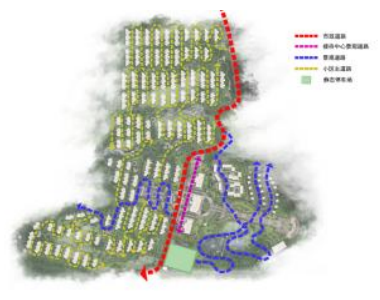

Figure 4. Traffic Analysis Chart

\section{Design Principles}

The main idea of design concept is considering synthetically all kinds of existing natural conditions and human conditions, and then make a comprehensive organization and design. Several principles should be followed when design.

Integrity. The design of landscape need to consider overall so that make the whole resort into a complete garden. At the same time, design should adhere the high starting of planning and development goals and high-quality building and living environment. Combine landscape style, architectural style and local characteristics together to create a unique landscape environment.

Artistry. The artistry of project landscapes is manifested mainly by a combination of artistic linguistic symbols (spatial combination, proportion, scale, color, texture, modeling, etc.) and artistic composition, which can enhance the image and artistic taste of the entire park.

Sustainable Development. Adopt ecological principles and use advanced agricultural technology with energy conservation and environmental management to establish a virtuous cycle of agricultural ecological system. Plan and design eco-agricultural park scientifically, and let the natural landscape and man-made landscape integrate well. The scientific rainwater collection is adopted to design the water lake landscape, and the water reuse in the constructed wetland can achieve the internal ecological cycle of the water in the landscape.

\section{Sustainable Development Planning Supported by Ecological Landscape}

The design of garden follows the link between sightseeing and agricultural functions. It provides agricultural space, ecological and agricultural products cultivation, harvesting and sales. Besides, it also uses a modern design approach to achieve the regional characteristics and European design style combination according to regional characteristics of landscape and culture. The garden will be divided into several parts, including tourism, sightseeing, agricultural picking, restaurant and accommodation. Therefore, eco-tourism not only produce economic benefits but also promote the sustainable development of the whole garden.

Ecological and Agricultural Orchard. There are mainly organic vegetables, grapes, peaches and so on in orchard. Tourists can participate in their own labor, picking and so on to fully enjoy the natural beauty and pastoral scenery and feel the fun of picking. Chinese farming culture "Living Museum" and Chinese farming civilization "Invention Operation Garden" are not only a simple combination and display of Chinese traditional culture, but a interpretation of "Live Museum" in essence. At the same time, it dig deep Chishui rich natural landscape and historical and cultural landscape to integrate the orchard, vegetable garden, four seasons flower fields and historical and cultural landscape into eco-tourism routes. The orchard can achieve sightseeing, experience tourism and agroecological industries as well as the knowledge base of ecological agriculture for young people. Meanwhile, effectively promote the experimental area construction of urban and rural to solve the employment needs of all aboriginal and industrial adjustment. Use a new mode of production to get rid of poverty, protect ecology and develop economy. Besides, explore a sustainable development business model for the majority of Chinese rural areas to develop leisure industry. 


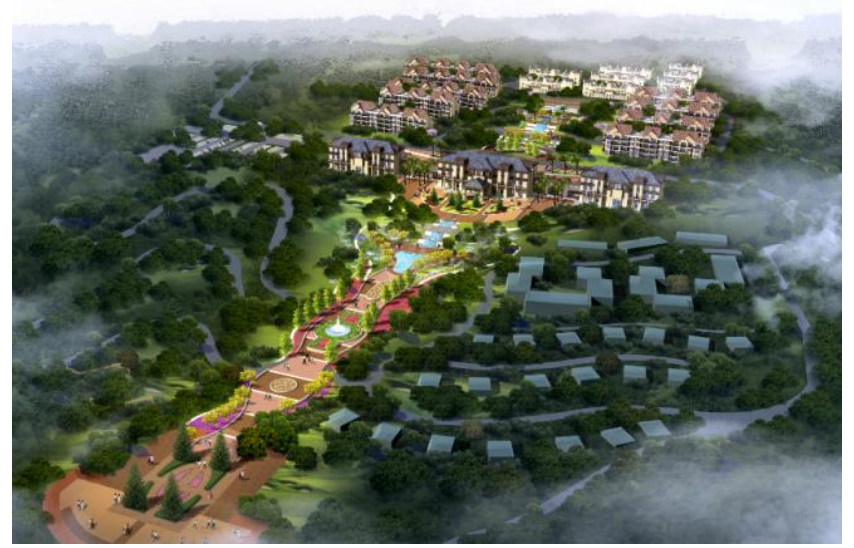

Figure 5. Main Landscape Map

Leisure Landscape and Fitness Pension Center. It is located on both sides of the central axis of landscape and it is not far from the main entrance of the landscape. It can provide leisure, entertainment, some characteristics of farm services and accommodation for visitors. There are also some regional characteristics of the landscape, which can provide food and beverage to let visitors taste green vegetable diet. Chishui's summer is warm and winter is cool. There is mountains, water and convenient future traffic, which is suit for developing hundreds of healthy recreational sports projects, such as tennis, rock climbing, mountain cross-country, fishing and so on to form a various of health sports center. As the basis of sports project scientific research, training, convalescence, commercialization base, tourism vacation and recreation, a number of high standards of sports venues and other supporting sports facilities will be built through the introduction and development of higher-level sports events. At the same time, the construction of sports and leisure training center can provide professional sports training opportunities for sports lovers and provide the necessary support for leisure life.

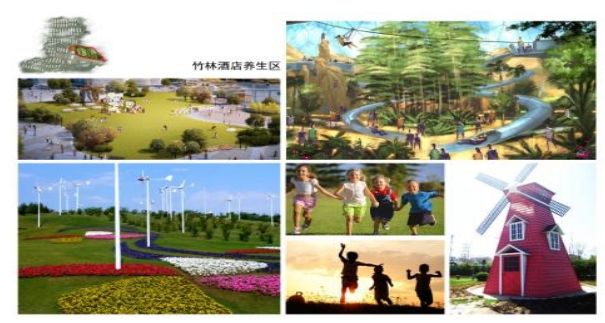

Figure 6. Leisure Landscape Intention Map

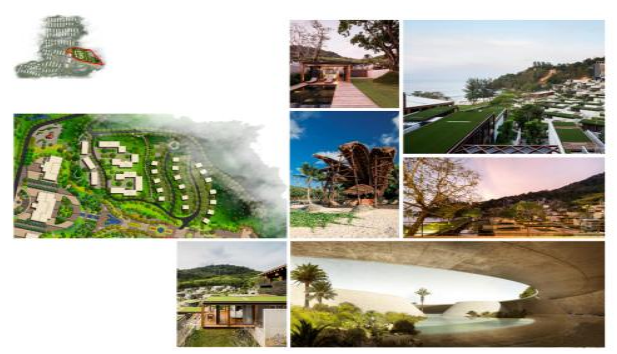

Figure 7. Accommodation

Hot Spring Area and Ecological Wetland Area. Build hot spring club combined with regional characteristics and design artificial wetland area combined with the landscape characteristics of garden. Use superior geological, climate, hydrological and other natural conditions and develop tourism resources to attract natural and cultural tourists. Besides, develop local superior natural 
resources and build hot spring SPA, health park, fitness and convalescent center. Develop huge potential of tourist source and the "silver-haired" source and construct "sunset red" health resort to make it become the second home of affluent class.
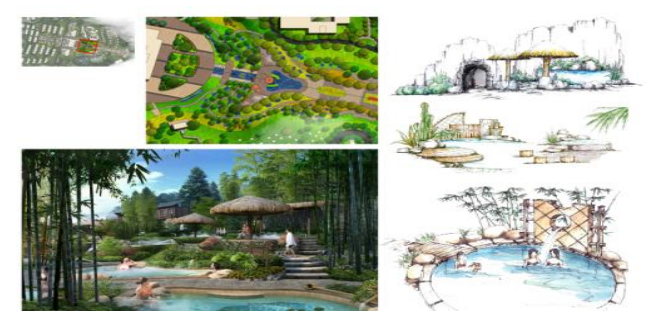

Figure 8. Hot Spring

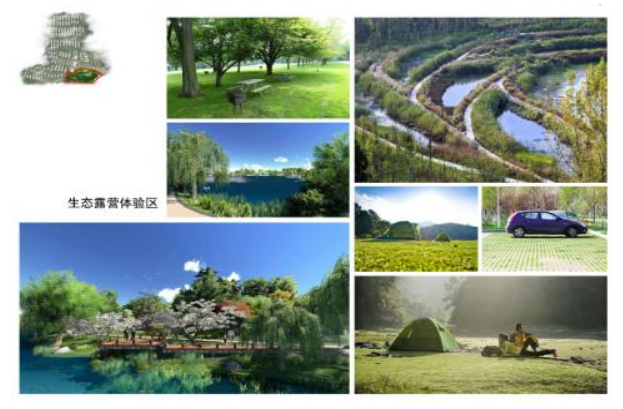

Figure 9. Ecological Wetland

Camping Experience Zone. A unique tourist camping area is designed according to unique geographical location and altitude of the garden. The surrounding bamboo and wetland provides a more unique entertainment place for tourists.

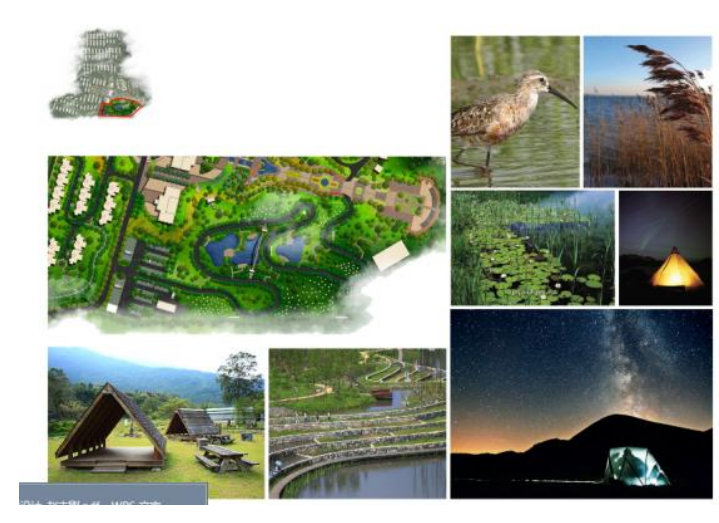

Figure 10. Camping Experience Zone

\section{Analysis of Tourists Source}

Market Situation of Tourists Source. At present, the main source of tourists are Chongqing, Chengdu, Guiyang and other places. According to statistics in 1998, visitors came to Chishui are up to 128,000 . According to 2004 statistics, climbing tourists are up to 17 million, of which $80-90 \%$ came from Chongqing. Besides, there are a small number of suburban tourists.

Market Analysis of Tourists Source. Tourism resources of Chishui has leisure and vacation characteristics. With the improvement of external traffic conditions, its location advantage of "one-hour economic circle" will gradually be enlarged and the number of tourists will be multiplied.

The continuous development of economy of Chongqing municipality and Chengdu and the 
popularity of private cars make them enter the transition golden period of short-distance travel in the weekend. People of urban, suburban areas and floating population of Chongqing is 800 million. About $40 \%$ or more namely 3.2 million people travel to the outskirts of tourism and leisure entertainment.

\section{Conclusion}

The planning and development of agroecological sightseeing garden is an important part of the study of tourism agriculture. With the development of ecological agriculture in China, the construction of ecological agriculture will also increase. How to make the overall planning and design of the agroecological sightseeing garden have innovative characteristics, meet the needs of tourists in more areas and respect the geographical location, the project make the corresponding attempt. Hope this paper has some constructive opinions on the design of agroecological sightseeing garden.

\section{References}

[1] Hongwen Bi. The Characteristics and Development Direction of Tourism Agriculture in China [M]. Northern Horticulture. 2006 (1): 61-62.

[2] Hua Fu, Yanhua Wu. The Characteristics, Formation and Basic Patterns of Tourism Agriculture in China [M]. Research of Agricultural Modernization. 2005, 26: 18-20.

[3] Boyang Shu. An Analysis of the Current Situation of Sightseeing Agriculture Tourism in China and Its Prospect [M]. Journal of Tourism. 1997 (5): 41-43.

[4] Yingying Liu, Meisheng Yuan. Discussion on the Development of Leisure Agriculture in China [M]. Business Times, Academic Review. 2006 (7): 72-74.

[5] Min Peng, Hua Fu. A Study on Rural Community Participation in Tourism Development in China [M]. Chinese Agricultural Science. 2007, 23 (1): 172-175.

[6] Menglin Yao. Some Thoughts on the Development of Leisure Agriculture in Mainland China [M]. Fujian Agricultural Science and Technology. 2011 (2).

\section{Introduction of Author}

Lu Tan (1981), Female, Han, Chongqing, Chengdu Vocational College of Agricultural Science and Technology, Lecturer, Master's Degree. Research Direction: Art and Design, Landscape Architecture.

Phone: 18981822677 Hengda City 75, Wenjiang District, Chengdu City, Sichuan Province

Baisong Lu (1980), Male, Han, Chongqing, Chongqing Aerospace Vocational and Technical College, Lecturer, Senior Engineer, Master's Degree. Research Direction: Landscape Architecture. 